09,04

\title{
Эволюция спектральных и структурных характеристик ортоборатов $\mathrm{Lu}_{0.99-x} \mathrm{Gd}_{x} \mathrm{Eu}_{0.01} \mathrm{BO}_{3}$
}

\author{
() С.З. Шмурак, В.В. Кедров, А.П. Киселев, Т.Н. Фурсова, И.И. Зверькова, Е.Ю. Постнова \\ Институт физики твердого тела РАН, \\ Черноголовка, Россия \\ E-mail: shmurak@issp.ac.ru
}

Поступила в Редакцию 28 фревраля 2021 г.

В окончательной редакции 28 февраля 2021 г.

Принята к публикации 2 марта 2021 г.

\begin{abstract}
Проведены исследования структуры, спектров ИК-поглощения и люминесценции твердых растворов $\mathrm{Lu}_{0.99-x} \mathrm{Gd}_{x} \mathrm{Eu}_{0.01} \mathrm{BO}_{3}$ при $0 \leq x \leq 0.15$. Установлено соответствие между структурой и спектральными характеристиками этих соединений. Показано, что ортобораты $\mathrm{Lu}_{0.99-x} \mathrm{Gd}_{x} \mathrm{Eu}_{0.01} \mathrm{BO}_{3}$, состоящие из бората лютеция $\mathrm{LuBO}_{3}$, имеющего две устойчивые структурные модификации (кальцит и ватерит), и бората гадолиния $\mathrm{GdBO}_{3}$, имеющего только одну структурную модификацию (ватерит), при $x \leq 0.05$ образуют твердый раствор со структурой кальцита и размером микрокристаллов 15-20 $\mu \mathrm{m}$. При увеличении $x$ количество фазы ватерита последовательно увеличивается и при $x \geq 0.1$ весь объем образца имеет структуру ватерита. При концентрациях $\mathrm{Gd}^{3+} 0.05<x \leq 0.1$ образцы $\mathrm{Lu}_{0.99-x} \mathrm{Gd}_{x} \mathrm{Eu}_{0.01} \mathrm{BO}_{3}$ являются двухфазными.

Впервые показано, что при $x>0.05$ фаза ватерита появляется как в объеме крупных микрокристаллов $(15-20 \mu \mathrm{m})$, так и в виде мелких микрокристаллов $(1-2 \mu \mathrm{m})$.
\end{abstract}

Ключевые слова: люминофоры для светодиодов, ортобораты редкоземельных элементов, рентгенофазовый анализ, ИК-спектроскопия, спектры люминесценции.

DOI: 10.21883/FTT.2021.07.51045.037

\section{1. Введение}

Однозначное соответствие между спектрами свечения боратов редкоземельных элементов и их структурным состоянием позволяет направленным образом управлять спектральными характеристиками боратов путем изменения их структуры [1-9]. Так как бораты могут быть использованы в качестве эффективных люминофоров для светодиодных источников света, то изучение способов направленного изменения их спектральных характеристик представляет значительный интерес.

Существенные различия в спектрах люминесценции различных структурных модификаций наблюдаются для боратов редкоземельных элементов, легированных ионами $\mathrm{Eu}^{3+}$. В спектрах люминесценции образцов $\mathrm{LuBO}_{3}(\mathrm{Eu})$, имеющих структуру кальцита, наблюдаются две узкие полосы с $\lambda_{\max }=589.8$ и $595.7 \mathrm{~nm}$ (электронный переход $\left.{ }^{5} \mathrm{D}_{0} \rightarrow{ }^{7} \mathrm{~F}_{1}\right)$ [2,4,5]. Спектр люминесценции ватеритной модификации $\mathrm{REBO}_{3}:(\mathrm{Eu})$, где RE $\mathrm{Lu}, \mathrm{Y}, \mathrm{Gd}$ содержит три полосы: в области длин волн $588-596 \mathrm{~nm}$ (электронный переход ${ }^{5} \mathrm{D}_{0} \rightarrow{ }^{7} \mathrm{~F}_{1}$ ), $608-613$ и $624-632 \mathrm{~nm}\left({ }^{5} \mathrm{D}_{0} \rightarrow{ }^{7} \mathrm{~F}_{2}\right)[1,2,4,10]$.

Значительные изменения спектров люминесценции ионов $\mathrm{Eu}^{3+}$ при изменении структурного состояния боратов редкоземельных элементов позволяют использовать в этих соединениях ионы $\mathrm{Eu}^{3+}$ в качестве структурно-чувствительных и оптически активных меток для идентификации их структуры. Как известно, $\mathrm{RE}^{3+}-$ ионы (в том числе и $\mathrm{Eu}^{3+}$ ) чувствительны к ближайшему окружению $[11,12]$. Поэтому по изменению спектральных характеристик $\mathrm{RE}^{3+}$-ионов можно судить об изменении их локального окружения даже тогда, когда дальний порядок (определенная структурная модификация) отсутствует.

Следует особо отметить, что внедрение в образец ионов $\mathrm{Eu}^{3+}$ позволяет следить за его структурным состоянием как в объеме, так и на поверхности образца. В работах [13-15] показано, что если ближний порядок вокруг ионов $\mathrm{Eu}^{3+}$ во всем образце одинаков, о чем свидетельствует совпадение спектров люминесценции (СЛ) приповерхностного слоя образца и его объема, то образец является однофазным.

Информацию о ближайшем окружении ионов $\mathrm{Eu}^{3+}$ в объеме кристалла можно получить, возбуждая люминесценцию ионов $\mathrm{Eu}^{3+}$ светом с энергией, соответствующей резонансному возбуждению ионов $\mathrm{Eu}^{3+}$ в области прозрачности кристалла $\left(\lambda_{\mathrm{ex}} \sim 394\right.$ и $\sim 466 \mathrm{~nm}$, электронные переходы ${ }^{7} \mathrm{~F}_{0} \rightarrow{ }^{5} \mathrm{~L}_{6}$ и ${ }^{7} \mathrm{~F}_{0} \rightarrow{ }^{5} \mathrm{D}_{2}$ соответственно) [1,2,13-15].

Возбуждение свечения редкоземельных ионов светом с энергией, находящейся в области интенсивного поглощения образца, позволяет получить информацию о локальном окружении ионов $\mathrm{Eu}^{3+}$ в приповерхностном слое кристалла. Для исследованных в настоящей работе ортоборатов, содержащих $\mathrm{Eu}^{3+}$, область длин волн, при которых наблюдается интенсивное поглощение, находится при $\lambda=225-275 \mathrm{~nm}$ (полоса с переносом заряда (ППЗ)) [1,2,13-16].

Использование этой, разработанной нами, методики исследования локального окружения редкоземельного 
иона позволило получить информацию о формировании структуры на поверхности и в объеме микрокристаллов в твердом растворе $\mathrm{Lu}_{1-x} \mathrm{In}_{x} \mathrm{BO}_{3}$ [9].

В работе [9] установлено, что твердый раствор $\mathrm{Lu}_{1-x} \mathrm{In}_{x} \mathrm{BO}_{3}$, состоящий из бората лютеция $\left(\mathrm{LuBO}_{3}\right)$, имеющего две устойчивые структурные модификации ватерит (пр.гр. $C 2 / c$ ) и кальцит (пр.гр. $R \overline{3} c$ ), и ортобората индия $\left(\mathrm{InBO}_{3}\right)$, имеющего только одну структурную модификацию - кальцит, при $x>0.08-0.1$ кристаллизуется только в структуре кальцита.

Показано, что увеличение концентрации ионов $\mathrm{In}^{3+}$ в соединениях $\mathrm{Lu}_{0.98-x} \operatorname{In}_{x} \mathrm{Eu}_{0.02} \mathrm{BO}_{3}$, синтезированных при $780^{\circ} \mathrm{C}$ (температуре существования ватерита $\mathrm{LuBO}_{3}$ ), приводит к увеличению фазы кальцита. При $x=0.03$, $0.04,0.06,0.083$ и 0.1 объемная доля фазы кальцита составляет 12, 41, 79, 95 и 98\% соответственно.

Впервые проведенные в работе [9] исследования люминесценции соединений $\mathrm{Lu}_{0.98-x} \operatorname{In}_{x} \mathrm{Eu}_{0.02} \mathrm{BO}_{3}$ при возбуждении в полосе с переносом заряда $\left(\lambda_{\mathrm{ex}}=250 \mathrm{~nm}\right)$ и при резонансном возбуждении ионов $\mathrm{Eu}^{3+}\left(\lambda_{\mathrm{ex}}=394 \mathrm{~nm}\right)$ показали, что структурные преобразования в ортоборатах $\mathrm{Lu}_{0.98-x} \mathrm{In}_{x} \mathrm{Eu}_{0.02} \mathrm{BO}_{3}$ при увеличении концентрации ионов $\mathrm{In}^{3+}$ начинаются в приповерхностном слое микрокристаллов этих образцов:

- при $x \geq 0.04$ приповерхностный слой имеет структуру кальцита,

- при $x=0.05,0.06,0.083$ и 0.1 количество фазы кальцита последовательно увеличивается и в объеме образца.

В работах [4,5] показано, что твердые растворы, состоящие из бората лютеция $\left(\mathrm{LuBO}_{3}\right)$, имеющего, как отмечалось, две устойчивые структурные модификации (ватерит и кальцит) и боратов $\mathrm{Lu}_{1-x} \mathrm{RE}_{x} \mathrm{O}_{3}(\mathrm{RE}=\mathrm{Eu}$, $\mathrm{Gd}, \mathrm{Tb}$, Dу и Y), имеющих только одну структурную модификацию - ватерит [17-19], при $x>0.15-0.2$, синтезированные при $T=970-1100^{\circ} \mathrm{C}$ (температуре существования кальцитной фазы $\mathrm{LuBO}_{3}$ ), кристаллизуются в структуре ватерита. Представляется целесообразным провести исследование структурных преобразований на поверхности и в объеме микрокристаллов $\mathrm{Lu}_{1-x} \mathrm{RE}_{x} \mathrm{BO}_{3}$ при увеличении концентрации $\mathrm{RE}^{3+}$.

$\mathrm{B}$ настоящей работе проведены исследования влияния $\mathrm{Gd}^{3+}$ на структуру, ИК-спектры и спектры люминесценции твердого раствора $\mathrm{Lu}_{0.99-x} \mathrm{Gd}_{x} \mathrm{Eu}_{0.01} \mathrm{BO}_{3}$ при возбуждении поверхности и объема микрокристаллов этого соединения при $0 \leq x \leq 0.15$. Полученная информация дала возможность определить локализацию образующейся новой фазы при изменении $x$.

\section{2. Методики эксперимента}

\section{1. Синтез образцов}

Образцы поликристаллических порошков ортобората лютеция, легированного $\mathrm{Gd}^{3+}$ и $\mathrm{Eu}^{3+}$, были синтезированы взаимодействием оксидов редкоземельных элементов с расплавом тетрабората калия по реакции

$$
\begin{aligned}
(0.99-x) \mathrm{Lu}_{2} \mathrm{O}_{3} & +x \mathrm{Gd}_{2} \mathrm{O}_{3}+0.01 \mathrm{Eu}_{2} \mathrm{O}_{3}+\mathrm{K}_{2} \mathrm{~B}_{4} \mathrm{O}_{7} \\
& =2 \mathrm{Lu}_{0.99-x} \mathrm{Gd}_{x} \mathrm{Eu}_{0.01} \mathrm{BO}_{3}+\mathrm{K}_{2} \mathrm{~B}_{2} \mathrm{O}_{4} .
\end{aligned}
$$

Количество тетрабората калия, взятое в реакцию, обеспечивало 10-20\% избыток борсодержащего реагента относительно стехиометрического. Исходными соединениями для синтеза ортобората лютеция были тетраборат калия $\mathrm{K}_{2} \mathrm{~B}_{4} \mathrm{O}_{7} \cdot 4 \mathrm{H}_{2} \mathrm{O}$, оксиды $\mathrm{Lu}_{2} \mathrm{O}_{3}, \mathrm{Eu}_{2} \mathrm{O}_{3}$ и $\mathrm{Gd}_{2} \mathrm{O}_{3}$, азотная кислота. Все использованные химические вещества соответствовали квалификации „ЧДА“. Ионы $\mathrm{Lu}^{3+}, \mathrm{Eu}^{3+}$ и $\mathrm{Gd}^{3+}$ вводили в реакцию в виде водных растворов нитратных солей, которые получали растворением исходных оксидов редких земель в азотной кислоте. Синтез микрокристаллических порошков ортобората лютеция проводился следующим образом. Взвешенное количество кристаллического тетрабората калия (гидрата) и водные растворы нитратов редких земель помещали в керамическую чашку и тщательно перемешивали. Полученную водную суспензию нагревали на плитке и при осторожном кипении отгоняли воду. После чего полученный продукт отжигали при температуре $600^{\circ} \mathrm{C}$ в течение 20 min для удаления остаточной влаги и разложения нитратных солей. Твердый продукт перетирали в агатовой ступке и полученный порошок переносили в керамический тигель объемом $5 \mathrm{ml}$ для высокотемпературного отжига в течение $2 \mathrm{~h}$ при $T=970^{\circ} \mathrm{C}$. Полученные продукты обрабатывались водным раствором соляной кислоты с концентрацией 5 wt.\% в течение $0.2 \mathrm{~h}$. Выделение поликристаллов ортоборатов проводилось фильтрованием полученной водной суспензии с последующей промывкой и сушкой продукта на фильтре. Полученные порошки поликристаллов ортоборатов окончательно сушились на воздухе при $T=200^{\circ} \mathrm{C}$ в течение $0.5 \mathrm{~h}$.

Для выяснения влияния скорости охлаждения продукта после высокотемпературного отжига на морфологию получившихся микрокристаллов ортобората лютеция охлаждение проводилось в двух режимах: быстрое и медленное охлаждение.

При быстром охлаждении тигель с продуктом после выдержки при $970^{\circ} \mathrm{C}$ сразу извлекался из печи и остывал на воздухе. Время охлаждения продукта до $750^{\circ} \mathrm{C}$, то есть до температуры затвердевания расплава, составляло не более $3 \mathrm{~min}$.

В режиме медленного охлаждения тигель с продуктом оставался в печи, температура которой после двухчасовой выдержки при $970^{\circ} \mathrm{C}$ снижалась по программе с постоянной скоростью, при этом время охлаждения продукта до $750^{\circ} \mathrm{C}$ составило $20 \mathrm{~h}$.

Для фракционного разделения порошка ортоборатов по размерам микрокристаллов был использован седиментационный метод в водной среде. 


\section{2. Методы исследований}

Рентгендифракционные исследования проводили с использованием дифрактометра Rigaku SmartLab SE на $\mathrm{CuK} \alpha$ излучении, $\lambda=1.54178 \AA, 40 \mathrm{kV}, 35 \mathrm{~mA}$. Угловой интервал $2 \theta=10-140^{\circ}$. Фазовый анализ образцов и расчет параметров решетки проводили с использованием программ Match и PowderCell 2.4.

ИК-спектры поглощения образцов измерялись на Фурье-спектрометре VERTEX 80v в спектральном диапазоне $400-5000 \mathrm{~cm}^{-1}$ с разрешением $2 \mathrm{~cm}^{-1}$. Для измерений порошки поликристаллов перетирались в агатовой ступке, а затем тонким слоем наносились на кристаллическую шлифованную подложку $\mathrm{KBr}$. Измерение спектров таких образцов проводилось в вакуумированном отсеке прибора. С помощью ИК-микроскопа Hyperion Фурье-спектрометра в спектральном диапазоне $600-6000 \mathrm{~cm}^{-1}$ с поля $50 \times 50 \mu \mathrm{m}$ также были измерены спектры пропускания микрокристаллов, помещенных на кристаллическую пластинку $\mathrm{CaF}_{2}$.

Морфология образцов изучалась с использованием рентгеновского микроанализатора Supra 50VP с приставкой для EDS INCA (Oxford).

Спектры фотолюминесценции и спектры возбуждения люминесценции изучались на установке, состоящей из источника света - лампы ДКСШ-150, двух монохроматоров МДР-4 и МДР-6 (спектральный диапазон 200-1000 nm, дисперсия $1.3 \mathrm{~nm} / \mathrm{mm}$ ). Регистрация свечения осуществлялась фотоумножителем ФЭУ-106 (область спектральной чувствительности 200-800 nm) и усилительной системой. Монохроматор МДР-4 использовался для изучения спектров возбуждения люминесценции образцов, монохроматор МДР-6 применялся для изучения спектров люминесценции.

Спектральные и структурные характеристики, а также морфология образцов, исследовались при комнатной температуре.

\section{3. Рентгеноструктурные исследования}

Дифрактограммы порошковых образцов исследуемых соединений приведены на рис. 1. Фазовый состав образцов приведен в таблице. Образцы составов $\mathrm{Lu}_{0.99-x} \mathrm{Gd}_{x} \mathrm{Eu}_{0.01} \mathrm{BO}_{3}$ при $0 \leq x \leq 0.05$ являются однофазными и имеют структуру кальцита (PDF 72-1053) ромбоэдрическую, $R \overline{3} c$ (пр.гр. № 167), $Z=6$. В диапазоне концентраций $\mathrm{Gd}^{3+} 0.05<x \leq 0.1$ твердый раствор $\mathrm{Lu}_{0.99-x} \mathrm{Gd}_{x} \mathrm{Eu}_{0.01} \mathrm{BO}_{3}$ является двухфазным - наряду со структурой кальцита наблюдается фаза ватерита - моноклинная, $C 2 / c$ (пр.гр. № 15), $Z=12$ [20]. Количество фазы ватерита растет с увеличением концентрации ионов $\mathrm{Gd}^{3+}$. При концентрациях $\mathrm{Gd}^{3+} 6.5,8$ и 10 at.\% образцы содержат 25, 77 и 94\% фазы ватерита соответственно (таблица). При $x>0.1$ соединение $\mathrm{Lu}_{0.99-x} \mathrm{Gd}_{x} \mathrm{Eu}_{0.01} \mathrm{BO}_{3}$ снова становится однофазным и имеет структуру ватерита.
Зависимости объемов элементарных ячеек кальцитной и ватеритной фаз ортоборатов $\mathrm{Lu}_{0.99-x} \mathrm{Gd}_{x} \mathrm{Eu}_{0.01} \mathrm{BO}_{3}$ при $0 \leq x \leq 0.15$, приведенные к $Z=6$, представлены на

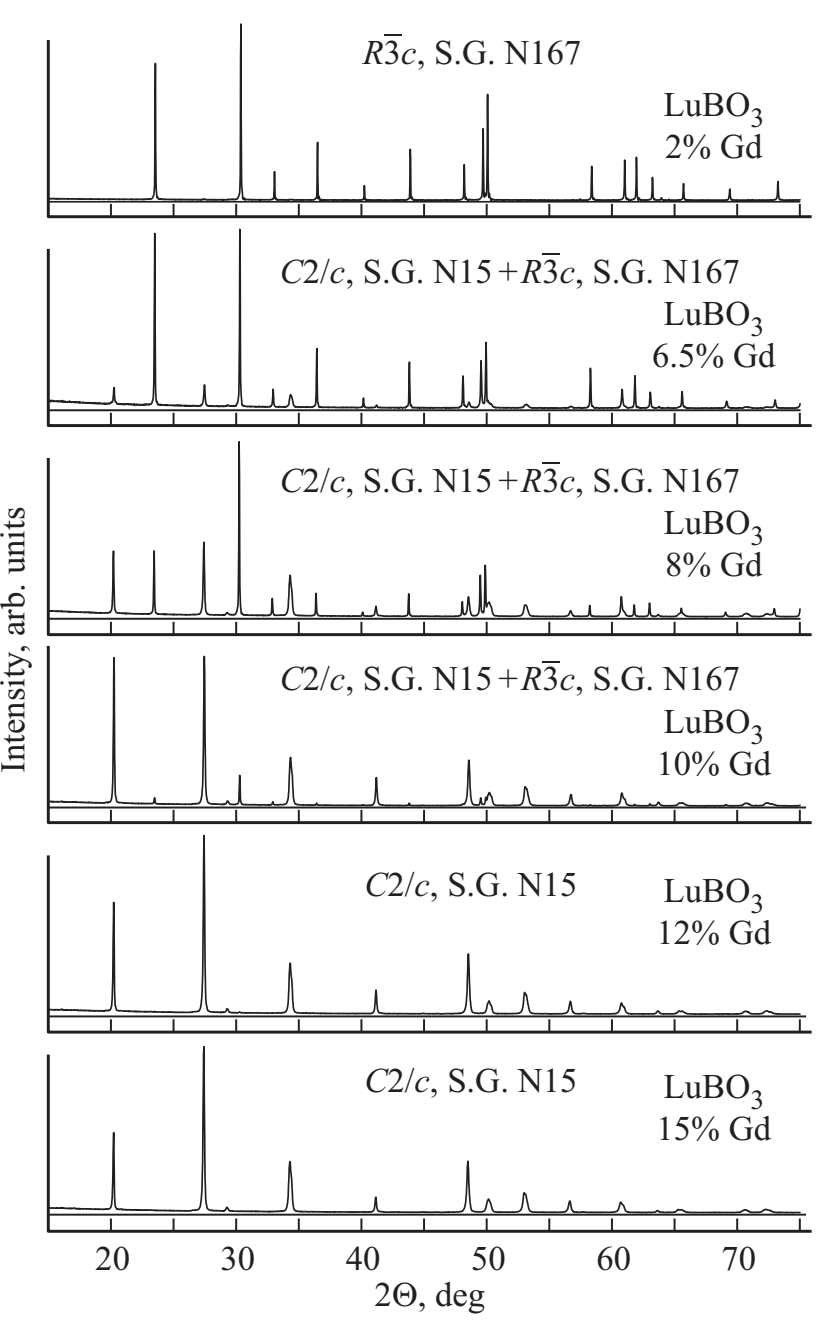

Рис. 1. Дифрактограммы образцов $\mathrm{Lu}_{0.99-x} \mathrm{Gd}_{x} \mathrm{Eu}_{0.01} \mathrm{BO}_{3}$ $(0.02 \leq x \leq 0.15)$.

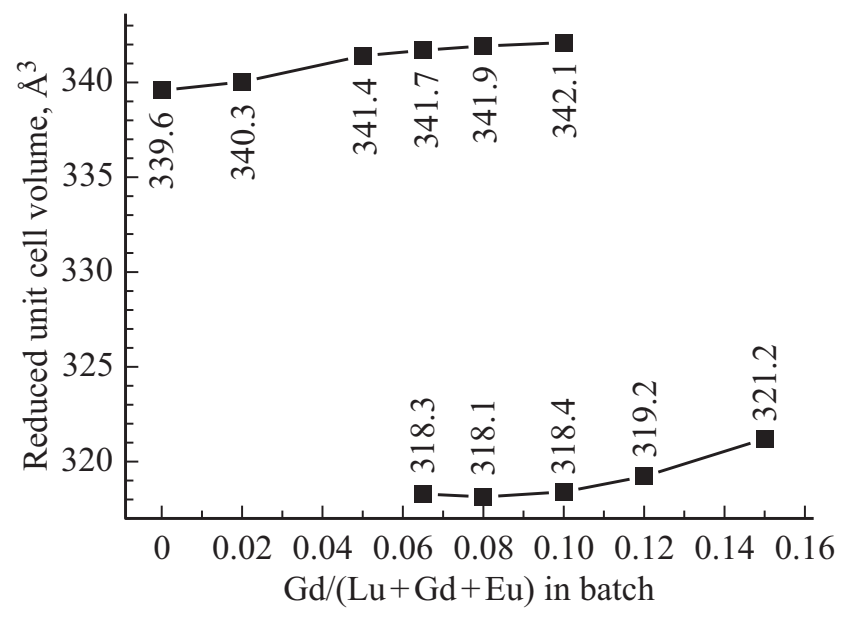

Рис. 2. Объемы элементарных ячеек фаз $\mathrm{Lu}_{0.99-x} \mathrm{Gd}_{x} \mathrm{Eu}_{0.01} \mathrm{BO}_{3}$ $(0 \leq x \leq 0.15)$, приведенные к $Z=6, \AA^{3}$. 

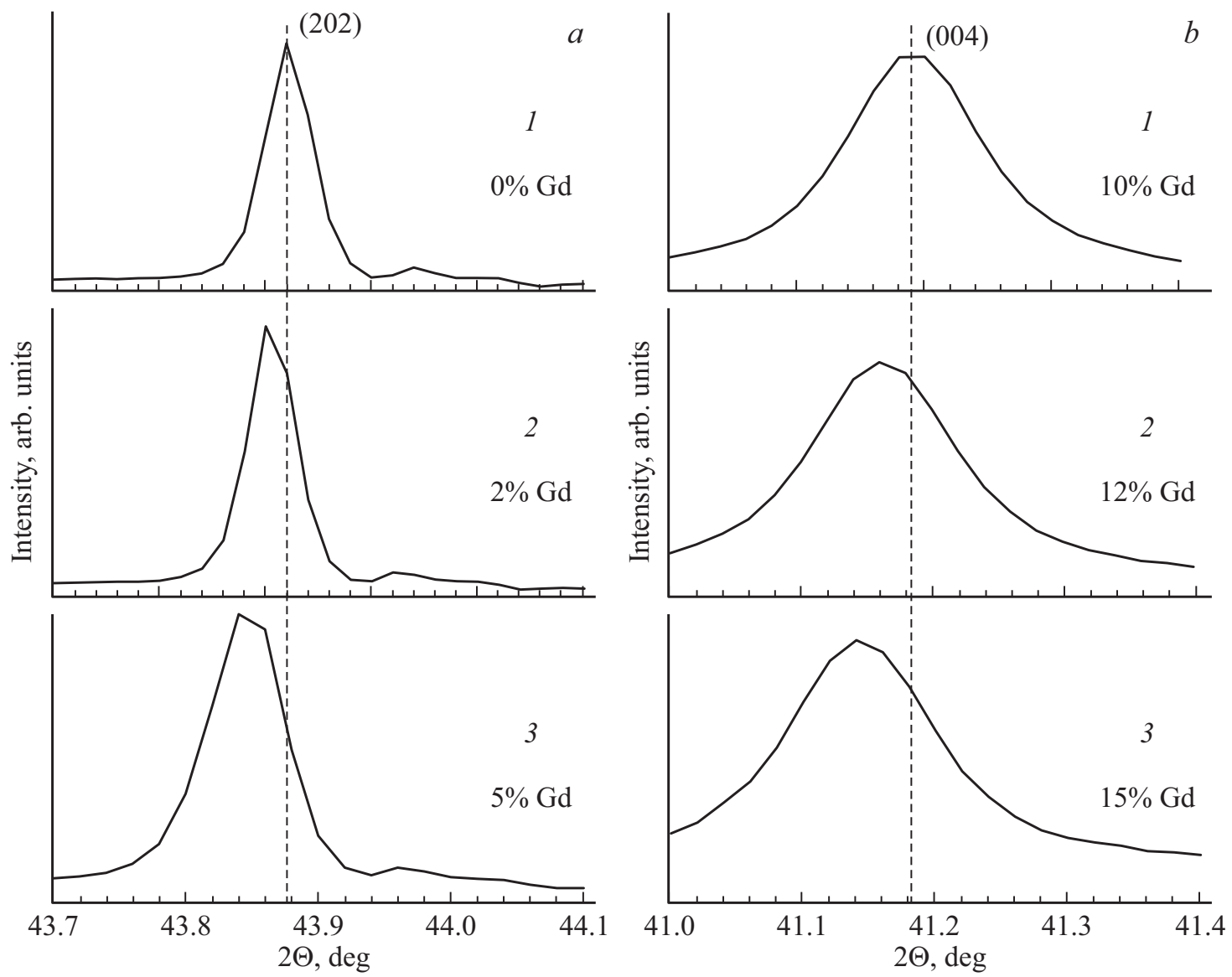

Рис. 3. Положение дифракционных пиков (202) для кальцитной и (004) для ватеритной модификаций $\mathrm{Lu}_{0.99-x} \mathrm{Gd}_{x} \mathrm{Eu}_{0.01} \mathrm{BO}_{3}$. a) $1-\mathrm{Lu}_{0.99} \mathrm{Eu}_{0.01} \mathrm{BO}_{3} ; \quad 2-\mathrm{Lu}_{0.97} \mathrm{Gdd}_{0.02} \mathrm{Eu}_{0.01} \mathrm{BO}_{3} ; 3-\mathrm{Lu}_{0.94} \mathrm{Gd}_{0.05} \mathrm{Eu}_{0.01} \mathrm{BO}_{3} . \quad$ b) $1-\mathrm{Lu}_{0.89} \mathrm{Gd}_{0.1} \mathrm{Eu}_{0.01} \mathrm{BO}_{3} ;$ $2-\mathrm{Lu}_{0.897} \mathrm{Gd}_{0.12} \mathrm{Eu}_{0.01} \mathrm{BO}_{3} ; 3-\mathrm{Lu}_{0.84} \mathrm{Gd}_{0.15} \mathrm{Eu}_{01} \mathrm{BO}_{3}$.

рис. 2. Замещение ионов $\mathrm{Lu}^{3+}$ ионами $\mathrm{Gd}^{3+}$ сопровождается увеличением объема элементарной ячейки, так как ионный радиус $\mathrm{Gd}^{3+}(0.971 \AA)$ больше ионного радиуса $\mathrm{Lu}^{3+}(0.867 \AA)$ [21]. Таким образом, образцы $\mathrm{Lu}_{0.99-x} \mathrm{Gd}_{x} \mathrm{Eu}_{0.01} \mathrm{BO}_{3}$ в диапазоне концентраций $\mathrm{Gd}^{3+}$ $0 \leq x \leq 0.05$ имеют структуру кальцита, при $x>0.1-$ структуру ватерита, а при $0.05<x \leq 0.10$ являются двухфазными.

Следует отметить, что фазовый состав ортоборатов $\mathrm{Lu}_{0.99-x} \mathrm{Gd}_{x} \mathrm{Eu}_{0.01} \mathrm{BO}_{3}$ существенно зависит от режима охлаждения образца. Например, быстро охлажденный образец $\mathrm{Lu}_{0.91} \mathrm{Gd}_{0.08} \mathrm{Eu}_{0.01} \mathrm{BO}_{3}$ содержит $23 \%$ кальцита и 77\% ватерита, в то время как медленно охлажденный содержит 62\% кальцита и $38 \%$ ватерита (таблица).

На рис. 3, $a, b$ представлены положения дифракционных линий (202) кальцитной фазы при $0 \leq x \leq 0.05$ и (004) ватеритной фазы при $x>0.1$. Сдвиг линий в область меньших углов с увеличением концентрации гадолиния в образцах $\mathrm{Lu}_{0.99-x} \mathrm{Gd}_{x} \mathrm{Eu}_{0.01} \mathrm{BO}_{3}$ обусловлен увеличением параметров решетки при вхождении в решетку кальцита $\mathrm{LuBO}_{3}$ ионов гадолиния, имеющих больший ионный радиус, чем ионы лютеция. Следует отметить, что в образцах $\mathrm{Lu}_{0.98-x} \operatorname{In}_{x} \mathrm{Eu}_{0.02} \mathrm{BO}_{3}$, наблюдался сдвиг дифракционного пика (102) кальцитной фазы в область больших углов с увеличением концентрации индия в образцах $[9,22]$. Такое смещение обусловлено уменьшением параметров решетки при замещении ионов $\mathrm{Lu}^{3+}$, имеющих ионный радиус $(0.867 \AA)$ на имеющие меньший ионный радиус ионы $\operatorname{In}^{3+}(0.843 \AA)$ [21].

\section{4. Морфология образцов}

В образцах $\mathrm{Lu}_{0.99} \mathrm{Gd}_{x} \mathrm{Eu}_{0.01} \mathrm{BO}_{3}$ в диапазоне концентраций $\mathrm{Gd}^{3+} 0 \leq x \leq 0.05$, имеющих согласно данным рентгенофазового анализа структуру кальцита (таблица), наблюдаются крупные микрокристаллы размером $\sim 15-20 \mu \mathrm{m}$ (рис. 4, $a, b)$. При увеличении концентрации гадолиния, наряду с крупными, появляются мелкие микрокристаллы размером $\sim 1-2 \mu \mathrm{m}$ (рис. $4, c, d, e, f, g$ ). С ростом концентрации ионов $\mathrm{Gd}^{3+}$ количество мелких микрокристаллов увеличивается, а крупных уменьшается, при этом растет количество фазы ватерита (таблица). В образцах $\mathrm{Lu}_{0.87} \mathrm{Gd}_{0.12} \mathrm{Eu}_{0.01} \mathrm{BO}_{3}$ и $\mathrm{Lu}_{0.84} \mathrm{Gd}_{0.15} \mathrm{Eu}_{0.01} \mathrm{BO}_{3}$, имеющих структуру ватерита, наряду с подавляющим большинством мелких микрокристаллов, присутствуют крупные микрокристаллы, име- 


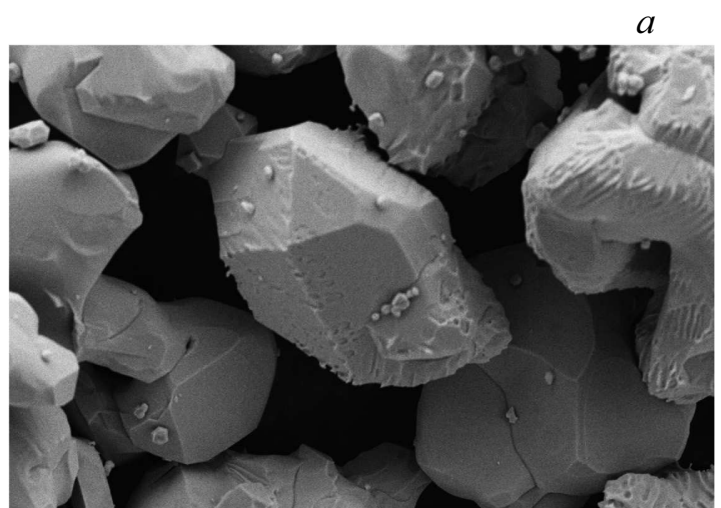

$-3 \mu \mathrm{m}$

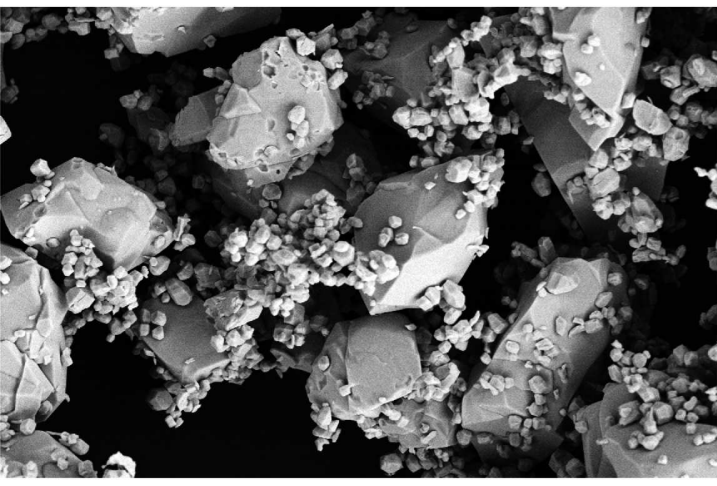

$-3 \mu \mathrm{m}$

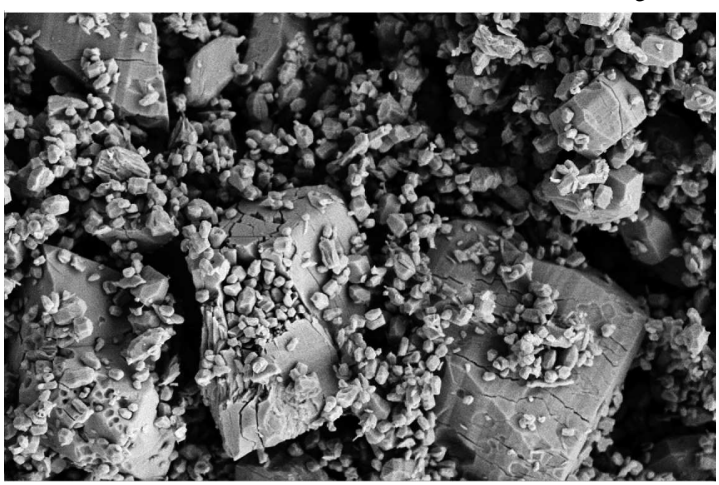

$-3 \mu \mathrm{m}$

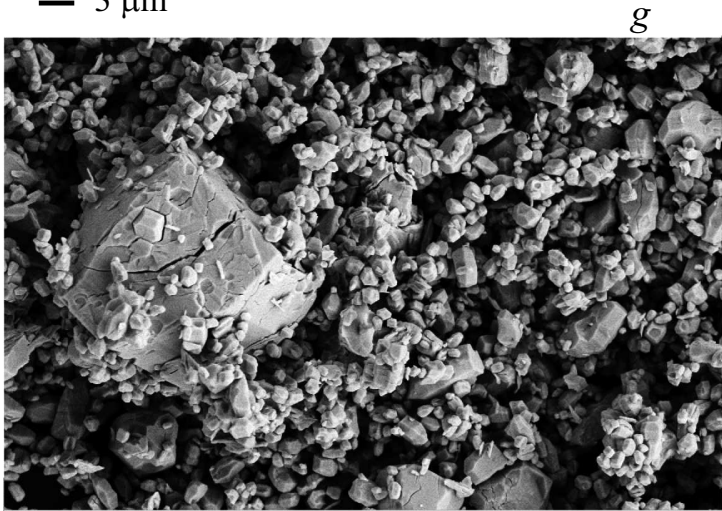

$-3 \mu \mathrm{m}$

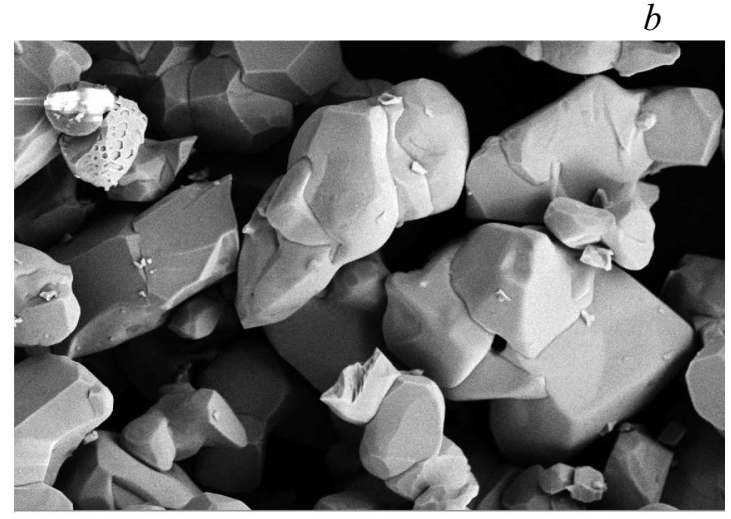

$-3 \mu \mathrm{m}$

d

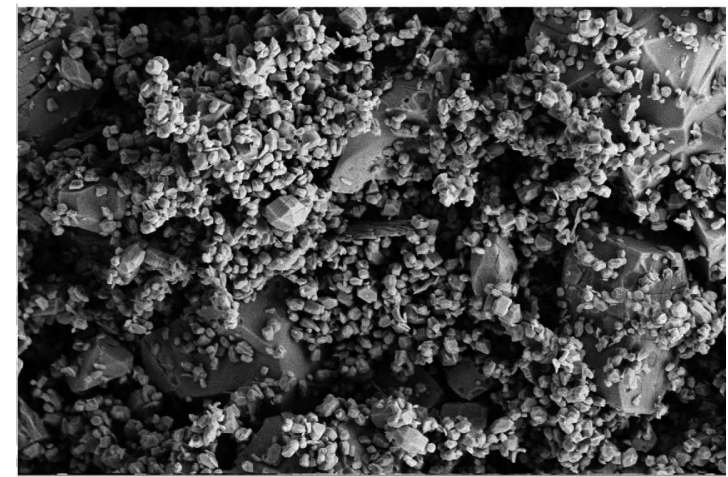

$-3 \mu \mathrm{m}$

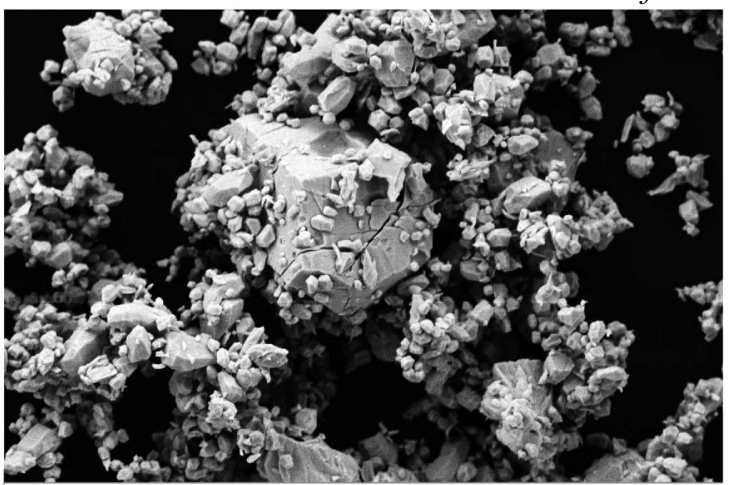

$-3 \mu \mathrm{m}$

h

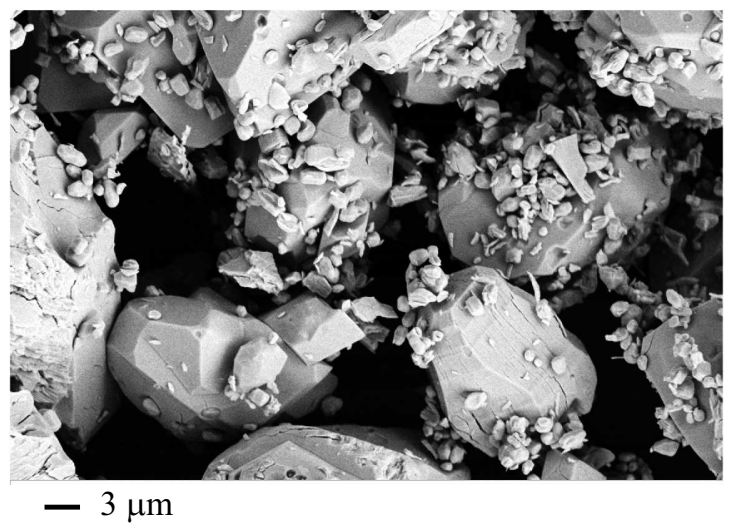

Рис. 4. Морфология образцов: $a-\mathrm{Lu}_{0.97} \mathrm{Gd}_{0.02} \mathrm{Eu}_{0.01} \mathrm{BO}_{3} ; b-\mathrm{Lu}_{0.94} \mathrm{Gd}_{0.05} \mathrm{Eu}_{0.01} \mathrm{BO}_{3} ; c-\mathrm{Lu}_{0.925} \mathrm{Gd}_{0.065} \mathrm{Eu}_{0.01} \mathrm{BO}_{3} ; d-$ $\mathrm{Lu}_{0.91} \mathrm{Gd}_{x 0.08} \mathrm{Eu}_{0.01} \mathrm{BO}_{3} ; e-\mathrm{Lu}_{0.89} \mathrm{Gd}_{0.1} \mathrm{Eu}_{0.01} \mathrm{BO}_{3} ; f-\mathrm{Lu}_{0.897} \mathrm{Gd}_{0.12} \mathrm{Eu}_{0.01} \mathrm{BO}_{3} ; g-\mathrm{Lu}_{0.84} \mathrm{Gd}_{0.15} \mathrm{Eu}_{0.01} \mathrm{BO}_{3} ; h-\mathrm{Lu}_{0.91} \mathrm{Gd}_{0.08} \mathrm{Eu}_{0.01} \mathrm{BO}_{3}$ (медленное охлаждение); $k-\mathrm{Lu}_{0.91} \mathrm{Gd}_{0.08} \mathrm{Eu}_{0.01} \mathrm{BO}_{3}$ (мелкая фракция); $l-\mathrm{Lu}_{0.925} \mathrm{Gd}_{0.065} \mathrm{Eu}_{0.01} \mathrm{BO}_{3}$ (крупная фракция); $m-$ $\mathrm{Lu}_{0.91} \mathrm{Gd}_{0.08} \mathrm{Eu}_{0.01} \mathrm{BO}_{3}$ (крупная фракция); $n-\mathrm{Lu}_{0.91} \mathrm{Gd}_{0.08} \mathrm{Eu}_{0.01} \mathrm{BO}_{3}$ (медленное охлаждение крупная фракция). 

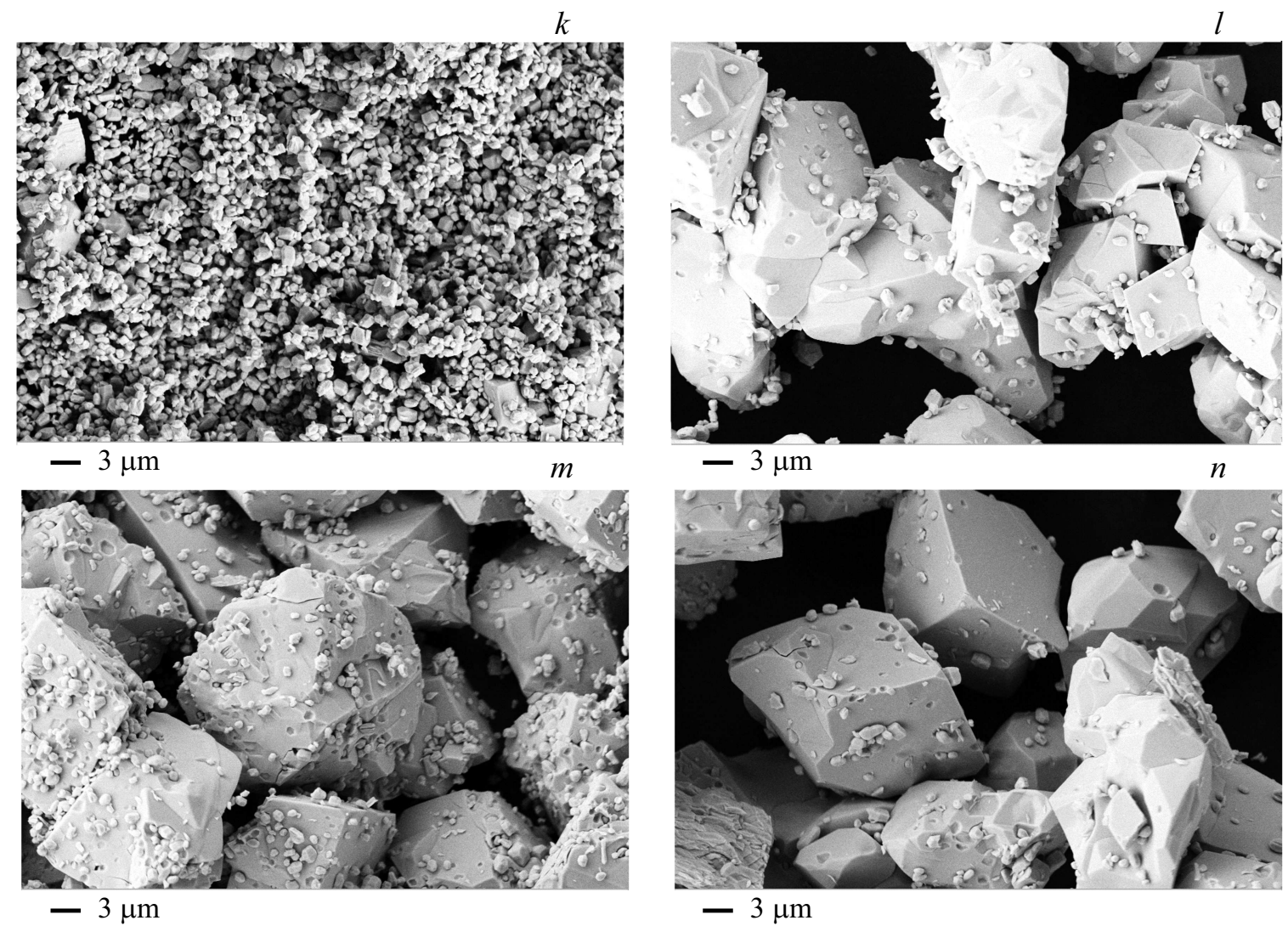

Рис. 4 (продолжение).

ющие нарушения сплошности (трещины). Следует отметить, что соотношение между количеством мелких и крупных микрокристаллов существенно зависит от скорости охлаждения образца. При медленном охлаждении количество мелких микрокристаллов существенно меньше, чем при быстром охлаждении образца (рис. $4, h, d)$.

Для получения информации о структуре мелких и крупных микрокристаллов в соединениях $\mathrm{Lu}_{0.99} \mathrm{Gd}_{x} \mathrm{Eu}_{0.01} \mathrm{BO}_{3}$ в настоящей работе проводилась сепарация порошков методом седиментации образцов, содержащих 6.5 и 8 at.\% ионов $\mathrm{Gd}^{3+}$. Фазовый состав крупной и мелкой фракций этих образцов приведен в таблице. Как видно из таблицы, мелкая фракция микрокристаллов $1-2 \mu \mathrm{m}$, полученная при сепарации образца $\mathrm{Lu}_{0.91} \mathrm{Gd}_{0.08} \mathrm{Eu}_{0.01} \mathrm{BO}_{3}$, содержит подавляющее количество фазы ватерита (91\%) (рис. $4, k)$.

Таким образом, на основании исследований фазового состава мелкой фракции соединения $\mathrm{Lu}_{0.91} \mathrm{Gd}_{0.08} \mathrm{Eu}_{0.01} \mathrm{BO}_{3}$ можно предположить, что в соединениях $\mathrm{Lu}_{0.99} \mathrm{Gd}_{x} \mathrm{Eu}_{0.01} \mathrm{BO}_{3}$ микрокристаллы, размер которых составляет $1-2 \mu \mathrm{m}$, имеют структуру ватерита.

На рис. 4, l, $m, n$ представлена крупная фракция сепарированных порошков быстро охлажденных соединений $\mathrm{Lu}_{0.925} \mathrm{Gd}_{0.065} \mathrm{Eu}_{0.01} \mathrm{BO}_{3}(l), \mathrm{Lu}_{0.91} \mathrm{Gd}_{x 0.08} \mathrm{Eu}_{0.01} \mathrm{BO}_{3} \quad(m)$ и медленно охлажденного соединения $\mathrm{Lu}_{0.91} \mathrm{Gd}_{0.08} \mathrm{Eu}_{0.01} \mathrm{BO}_{3}(n)$. Оценка соотношения объемов
Влияние концентрации $\mathrm{Gd}^{3+}$ на содержание фаз кальцита и ватерита в ортоборатах $\mathrm{Lu}_{0.99-x} \mathrm{Gd}_{x} \mathrm{Eu}_{0.01} \mathrm{BO}_{3}$

\begin{tabular}{l|c|c}
\hline \multicolumn{1}{c|}{ Состав } & $\begin{array}{c}\text { Фаза кальцита } \\
\text { (S.G. № 167), \% }\end{array}$ & $\begin{array}{c}\text { Фаза ватерита } \\
\text { (S.G. № } 15), \%\end{array}$ \\
\hline $\mathrm{Lu}_{0.99} \mathrm{Eu}_{0.01} \mathrm{BO}_{3}$ & 100 & 0 \\
$\mathrm{Lu}_{0.97} \mathrm{Gd}_{0.02} \mathrm{Eu}_{0.01} \mathrm{BO}_{3}$ & 100 & 0 \\
$\mathrm{Lu}_{0.94} \mathrm{Gd}_{0.05} \mathrm{Eu}_{0.01} \mathrm{BO}_{3}$ & 99 & 1 \\
$\mathrm{Lu}_{0.925} \mathrm{Gd}_{0.065} \mathrm{Eu}_{0.01} \mathrm{BO}_{3}$ & 75 & 25 \\
$\mathrm{Lu}_{0.91} \mathrm{Gd}_{0.08} \mathrm{Eu}_{0.01} \mathrm{BO}_{3}$ & 23 & 77 \\
$\mathrm{Lu}_{0.89} \mathrm{Gd}_{0.1} \mathrm{Eu}_{0.01} \mathrm{BO}_{3}$ & 6 & 94 \\
$\mathrm{Lu}_{0.897} \mathrm{Gd}_{0.12} \mathrm{Eu}_{0.01} \mathrm{BO}_{3}$ & 0 & 100 \\
$\mathrm{Lu}_{0.84} \mathrm{Gd}_{0.15} \mathrm{Eu}_{0.01} \mathrm{BO}_{3}$ & 0 & 100 \\
${ }^{*} \mathrm{Lu}_{0.925} \mathrm{Gd}_{0.065} \mathrm{Eu}_{0.01} \mathrm{BO}_{3}$ & 86 & 14 \\
${ }_{\text {крупная фракция }}$ & & \\
${ }^{*} \mathrm{Lu}_{0.91} \mathrm{Gd}_{0.08} \mathrm{Eu}_{0.01} \mathrm{BO}_{3}$ & 9 & 91 \\
${ }_{\text {мелкая фракция }}$ & & \\
${ }^{*} \mathrm{Lu}_{0.91} \mathrm{Gd}_{0.08} \mathrm{Eu}_{0.01} \mathrm{BO}_{3}$ & 77 & 23 \\
${ }_{\text {крупная фракция }}$ & & \\
${ }^{1} \mathrm{Lu}_{0.91} \mathrm{Gd}_{0.08} \mathrm{Eu}_{0.01} \mathrm{BO}_{3}$ & 62 & 26 \\
${ }^{* 1} \mathrm{Lu}_{0.91} \mathrm{Gd}_{0.08} \mathrm{Eu}^{0.01} \mathrm{BO}_{3}$ & 74 & \\
${ }_{\text {крупная фракция }}$ & &
\end{tabular}

Пр и м е чан и е. * Образцы, подвергнутые сепарации.

${ }^{1}$ Медленный отжиг образца. 
мелких и крупных микрокристаллов на этих рисунках показала, что количество мелких микрокристаллов, представляющих фазу ватерита, составляет $1-2,3-4$ и $\sim 1 \%$ соответственно. В то же время, согласно данным рентгенофазового анализа, количество фазы ватерита в этих образцах значительно больше и составляет 14, 23 и $26 \%$ соответственно (таблица). Это свидетельствует о том, что крупные микрокристаллы (15-20 $\mu \mathrm{m})$ являются двухфазными и содержат фазы ватерита и кальцита.

\section{5. Результаты ИК-спектроскопии}

На рис. 5 представлены спектры ИК-поглощения $\mathrm{Lu}_{0.99} \mathrm{Gd}_{x} \mathrm{Eu}_{0.01} \mathrm{BO}_{3} \quad(x=0.02, \quad 0.065, \quad 0.08, \quad 0.1, \quad 0.12$ и 0.15 ; спектры (1-6). По данным рентгенофазового анализа образцы $\mathrm{Lu}_{0.97} \mathrm{Gd}_{0.02} \mathrm{Eu}_{0.01} \mathrm{BO}_{3}$ (спектр 1) и $\mathrm{Lu}_{0.84} \mathrm{Gd}_{0.15} \mathrm{Eu}_{0.01} \mathrm{BO}_{3}$ (спектр 6) являются одно-

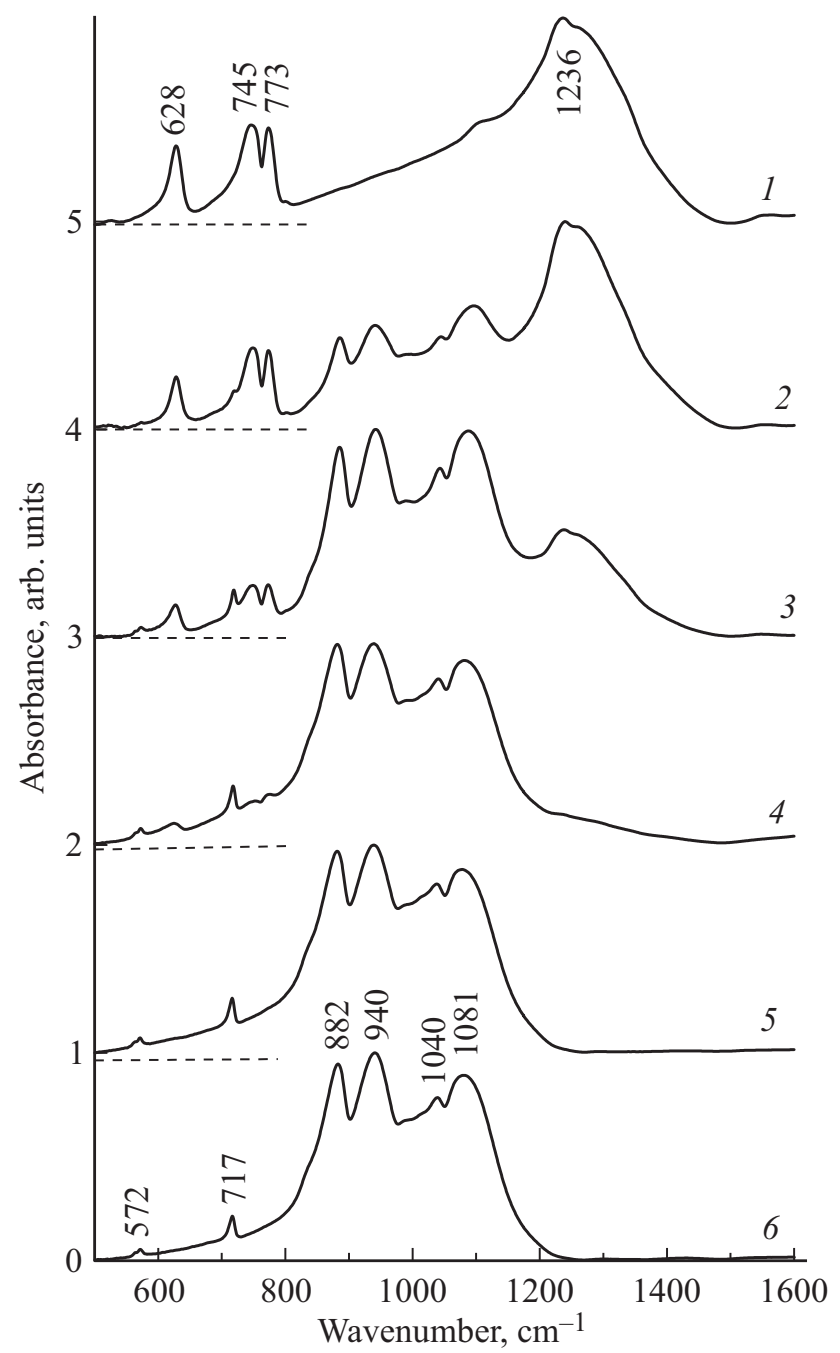

Рис. 5. Спектры ИК-поглощения ортоборатов $\mathrm{Lu}_{0.99-x} \mathrm{Gd}_{x} \mathrm{Eu}_{0.01} \mathrm{BO}_{3} . \quad 1-\mathrm{Lu}_{0.97} \mathrm{Gd}_{0.02} \mathrm{Eu}_{0.01} \mathrm{BO}_{3} ; 2-$ $\mathrm{Lu}_{0.925} \mathrm{Gd}_{0.065} \mathrm{Eu}_{0.01} \mathrm{BO}_{3} ; 3-\mathrm{Lu}_{0.91} \mathrm{Gd}_{0.08} \mathrm{Eu}_{0.01} \mathrm{BO}_{3} ; \quad 4-$ $\mathrm{Lu}_{0.89} \mathrm{Gd}_{0.1} \mathrm{Eu}_{0.01} \mathrm{BO}_{3} ; 5-\mathrm{Lu}_{0.897} \mathrm{Gd}_{0.12} \mathrm{Eu}_{0.01} \mathrm{BO}_{3} ; 6-$ $\mathrm{Lu}_{0.84} \mathrm{Gd}_{0.15} \mathrm{Eu}_{01} \mathrm{BO}_{3}$.

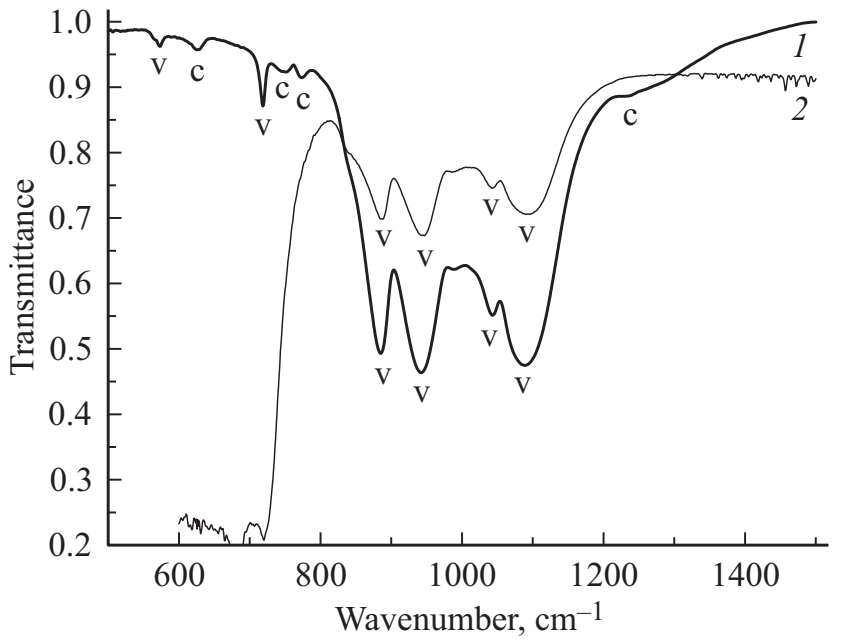

Рис. 6. Спектры пропускания мелкой фракции двухфазного образца $\mathrm{Lu}_{0.91} \mathrm{Gd}_{0.08} \mathrm{Eu}_{0.01} \mathrm{BO}_{3}: 1$ - вакуумированный отсек спектрометра; 2 - измерение с помощью микроскопа.

фазными и имеют структуры кальцита и ватерита, в которых атомы бора имеют тригональную и тетраэдрическую координацию, соответственно. В спектре 1 наблюдаются линии поглощения с максимумами $628,745,773,1236 \mathrm{~cm}^{-1}$, обусловленные колебаниями связей В-О в структуре кальцита [5,23-25]. В спектре 6 линии поглощения 572, 717, 882, 940, 1040 и $1081 \mathrm{~cm}^{-1}$ также обусловлены колебаниями связей В-О и характерны для образцов со структурой ватерита [1,5,23-25]. Спектры 2,3 и 4 описывают двухфазные образцы составов $\mathrm{Lu}_{0.925} \mathrm{Gd}_{0.065} \mathrm{Eu}_{0.01} \mathrm{BO}_{3}$, $\mathrm{Lu}_{0.91} \mathrm{Gd}_{0.08} \mathrm{Eu}_{0.01} \mathrm{BO}_{3} \quad$ и $\quad \mathrm{Lu}_{0.89} \mathrm{Gd}_{0.1} \mathrm{Eu}_{0.01} \mathrm{BO}_{3}$ соответственно и включают линии поглощения обеих фаз. Спектр 5 образца $\mathrm{Lu}_{0.87} \mathrm{Gd}_{0.12} \mathrm{Eu}_{0.01} \mathrm{BO}_{3}$ идентичен спектру 6, поскольку образец является также однофазным со структурой ватерита.

На рис. 6 приведены спектры пропускания мелкой фракции двухфазного образца $\mathrm{Lu}_{0.91} \mathrm{Gd}_{0.08} \mathrm{Eu}_{0.01} \mathrm{BO}_{3}$, состоящей преимущественно из микрокристаллов размером $1-2 \mu \mathrm{m}$ (рис. 4,k), которая по результатам рентгеноструктурного анализа содержит 91\% ватерита и 9\% кальцита. Спектр мелкой фракции образца $\mathrm{Lu}_{0.91} \mathrm{Gd}_{0.08} \mathrm{Eu}_{0.01} \mathrm{BO}_{3}$ (спектр 1), полученный в вакуумированном отсеке спектрометра, содержит линии поглощения, обусловленные колебаниями связей В-О как в фазе ватерита, так и в фазе кальцита (помечены на рисунке символами „,““ и „с“), причем линии кальцита существенно слабее, чем линии ватерита, в полном соответствии с данными рентгеноструктурного анализа. Спектр 2 получен с помощью микроскопа с поля $50 \times 50 \mu \mathrm{m}$, в котором находились только микрокристаллы размером $1-2 \mu \mathrm{m}$. Микрокристаллы располагались на подложке $\mathrm{CaF}_{2}$. Как видно из рисунка, в спектре 2 присутствуют линии поглощения только одной фазы ватерита. Следов кальцитной фазы в спектре не наблю- 

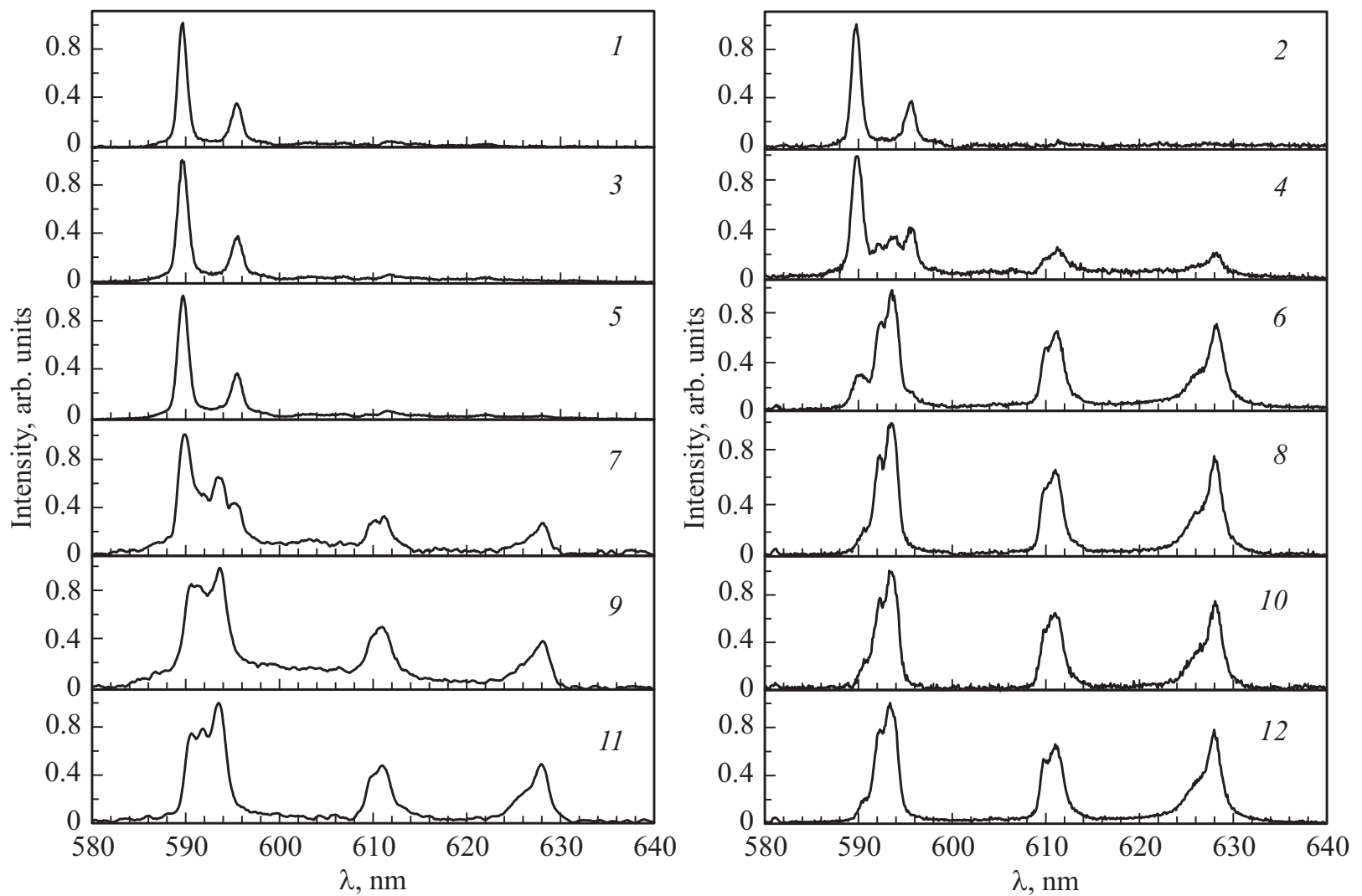

Рис. 7. Спектры люминесценции ортоборатов $\mathrm{Lu}_{0.99-x} \mathrm{Gd}_{x} \mathrm{Eu}_{0.01} \mathrm{BO}_{3} .1,2-\mathrm{Lu}_{0.94} \mathrm{Gd}_{0.05} \mathrm{Eu}_{0.01} \mathrm{BO}_{3}$; крупные фракции микрокристаллов, полученные в результате сепарации $\mathrm{Lu}_{0.925} \mathrm{Gd}_{0.065} \mathrm{Eu}_{0.01} \mathrm{BO}_{3}(3,4)$ и медленно охлажденных $\mathrm{Lu}_{0.91} \mathrm{Gd}_{0.08} \mathrm{Eu}_{0.01} \mathrm{BO}_{3}(5,6)$; 7, $8-\mathrm{Lu}_{0.89} \mathrm{Gd}_{0.1} \mathrm{Eu}_{0.01} \mathrm{BO}_{3} ; 9,10-\mathrm{Lu}_{0.87} \mathrm{Gd}_{0.12} \mathrm{Eu}_{0.01} \mathrm{BO}_{3} ; 11,12-\mathrm{Lu}_{0.84} \mathrm{Gd}_{0.15} \mathrm{Eu}_{0.01} \mathrm{BO}_{3} ; 1,3,5$ и $7-\lambda$ ех $=250 \mathrm{~nm} ; 9$ и $11-$ $\lambda_{\mathrm{ex}}=240 \mathrm{~nm} ; 2,4,6,8,10$ и $12-\lambda_{\mathrm{ex}}=394 \mathrm{~nm}$.

дается. Появление множества слабых пиков поглощения в области волновых чисел выше $1300 \mathrm{~cm}^{-1}$ обусловлено присутствием паров воды в воздухе. Падение пропускания в области ниже $800 \mathrm{~cm}^{-1}$ обусловлено поглощением подложки $\mathrm{CaF}_{2}$.

Таким образом, методом ИК-спектроскопии получены прямые доказательства того факта, что мелкие микрокристаллы размером $1-2 \mu \mathrm{m}$ имеют структуру ватерита.

\section{6. Спектры люминесценции и спектры возбуждения люминесценции}

\section{1. Спектры люминесценции ортоборатов $\mathrm{Lu}_{0.99-x} \mathrm{Gd}_{x} \mathrm{Eu}_{0.01} \mathrm{BO}_{3}$}

Спектры люминесценции (СЛ) соединений $\mathrm{Lu}_{0.99-x} \mathrm{Gd}_{x} \mathrm{Eu}_{0.01} \quad(x=0.05, \quad 0.065,0.08,0.1,0.12$ и 0.15) при возбуждении светом, соответствующим резонансному возбуждению ионов $\mathrm{Eu}^{3+}\left(\lambda_{\mathrm{ex}}=394 \mathrm{~nm}\right)$, и в максимуме полосы с переносом заряда $\left(\lambda_{\mathrm{ex}} \sim 250-240 \mathrm{~nm}\right)$ представлены на рис. 7. Спектры люминесценции образцов, содержащих 0-5at.\% ионов $\mathrm{Gd}^{3+}$, идентичны. На рис. 7, спектры 1 и 2, представлены спектры образцов при концентрации ионов $\mathrm{Gd}^{3+}$
5 at.\%. Как видно из рис. 7, спектры люминесценции приповерхностного слоя $\left(\lambda_{\mathrm{ex}}=250 \mathrm{~nm}\right)$, и объема образца $\left(\lambda_{\mathrm{ex}}=394 \mathrm{~nm}\right)$ совпадают. Они содержат полосы с $\lambda_{\max } 589.8$ и $595.7 \mathrm{~nm}$ (электронный переход $\left.{ }^{5} \mathrm{D}_{0} \rightarrow{ }^{7} \mathrm{~F}_{1}\right)$, характерные для кальцитной модификации этого образца. Согласно данным рентгенофазового анализа соединение $\mathrm{Lu}_{0.99-x} \mathrm{Gd}_{x} \mathrm{Eu}_{0.01} \mathrm{BO}_{3}$ при $0 \leq x \leq 0.05$ действительно имеет структуру кальцита (таблица).

При концентрации ионов $\mathrm{Gd}^{3+}$, больших 10 at.\%, СЛ приповерхностного слоя $\left(\lambda_{\mathrm{ex}}=240 \mathrm{~nm}\right)$ и объема образца $\left(\lambda_{\mathrm{ex}}=394 \mathrm{~nm}\right)$ содержат полосы в области длин волн 588-596 nm (электронный переход ${ }^{5} \mathrm{D}_{0} \rightarrow{ }^{7} \mathrm{~F}_{1}$ ), 608-613 и 624-632 nm $\left({ }^{5} \mathrm{D}_{0} \rightarrow{ }^{7} \mathrm{~F}_{2}\right)$, характерные для ватеритной модификации бората лютеция, легированного европием (рис. 7, спектры 9, 10, 11 и 12). Как отмечалось, согласно данным рентгенофазового анализа, образцы $\mathrm{Lu}_{0.99-x} \mathrm{Gd}_{x} \mathrm{Eu}_{0.01} \mathrm{BO}_{3}$ при $x>0.1$, имеют структуру ватерита (таблица).

Как показано в разделах 3,4 и 5 настоящей статьи, образцы $\mathrm{Lu}_{0.99-x} \mathrm{Gd}_{x} \mathrm{Eu}_{0.01} \mathrm{BO}_{3}$ при $0.05<x \leq 10$ являются двухфазными. Мелкие микрокристаллы размером $1-2 \mu \mathrm{m}$, имеют структуру ватерита, а крупные микрокристаллы $(15-20 \mu \mathrm{m})$ являются двух- 
фазными. Для установления структуры приповерхностного слоя и объема крупных микрокристаллов $\mathrm{Lu}_{0.99-x} \mathrm{Gd}_{x} \mathrm{Eu}_{0.01} \mathrm{BO}_{3}$ в настоящей работе были проведены исследования спектров люминесценции крупных микрокристаллов, полученных в результате сепарации образцов, содержащих 6.5 и 8 at.\% ионов $\mathrm{Gd}^{3+}$. Спектры люминесценции крупных микрокристаллов образца $\mathrm{Lu}_{0.925} \mathrm{Gd}_{0.065} \mathrm{Eu}_{0.01} \mathrm{BO}_{3}$, содержащего $86 \%$ кальцита и 14\% ватерита (таблица), при возбуждении приповерхностного слоя $\left(\lambda_{\mathrm{ex}}=250 \mathrm{~nm}\right)$ содержат полосы с $\lambda_{\max }=589.8$ и $595.7 \mathrm{~nm}$, характерные для кальцитной модификации $\mathrm{Lu}_{0.99-x} \mathrm{Gd}_{x} \mathrm{Eu}_{0.01} \mathrm{BO}_{3}$ (рис. 7, спектр 3). В то же время, спектр люминесценции объема образца $\left(\lambda_{\mathrm{ex}}=394 \mathrm{~nm}\right)$ содержит как полосы, характерные для кальцитной модификации (589.8 и $595.7 \mathrm{~nm})$, так и полосы, соответствующие ватеритной структуре этих микрокристаллов (рис. 7, спектр 4). В спектре люминесценции объема крупных микрокристаллов образца $\mathrm{Lu}_{0.91} \mathrm{Gd}_{0.08} \mathrm{Eu}_{0.01} \mathrm{BO}_{3}, \quad\left(\lambda_{\mathrm{ex}}=394 \mathrm{~nm}\right)$ доминируют полосы 588-596, 608-613 и 624-632 nm, характерные для ватеритной модификации бората лютеция, легированного европием (рис. 7, спектр 6). О том, что в объеме образца все же сохраняется кальцитная модификация, свидетельствует наличие в СЛ слабых полос с $\lambda_{\max }=589.8$ и $595.7 \mathrm{~nm}$ (рис. 8). В то же время, в спектре люминесценции приповерхностного слоя крупных микрокристаллов $\mathrm{Lu}_{0.91} \mathrm{Gd}_{0.08} \mathrm{Eu}_{0.01} \mathrm{BO}_{3}\left(\lambda_{\mathrm{ex}}=250 \mathrm{~nm}\right)$, доминируют полосы 589.8 и $595.7 \mathrm{~nm}$, соответствующие кальцитной фазе бората лютеция, легированного $\mathrm{Eu}^{3+}$ (рис. 7, спектр 5). Согласно данным рентгенофазового анализа крупная фракция образцов $\mathrm{Lu}_{0.91} \mathrm{Gd}_{0.08} \mathrm{Eu}_{0.01} \mathrm{BO}_{3}$ содержит 74\% кальцита и $26 \%$ ватерита (таблица).

В СЛ объема образцов, содержащих 10 at.\% $\mathrm{Gd}^{3+}$, наблюдаются только полосы, характерные для ватеритной модификации бората лютеция (рис. 7, спектр 7). При этом СЛ приповерхностного слоя содержит как полосы, характерные для фазы кальцита, так и для фазы ватерита (рис. 7, спектр 8).

Таким образом, при увеличении концентрации ионов $\mathrm{Gd}^{3+}$ в образцах $\mathrm{Lu}_{0.99-x} \mathrm{Gd}_{x} \mathrm{Eu}_{0.01} \mathrm{BO}_{3}$ в объеме крупных микрокристаллов, имеющих структуру кальцита при $x>0.05$, появляется фаза ватерита, которая при дальнейшем увеличении концентрации ионов $\mathrm{Gd}^{3+}$ появляется также и на поверхности образца. При концентрации ионов $\mathrm{Gd}^{3+}$ больше 12 at.\% образец является однофазным, так как и в объеме, и на поверхности образца наблюдаются спектры люминесценции, характерные только для фазы ватерита [13-15].

Интересно отметить, что, как показано в работе [9], в легированном индием ортоборате лютеция, который имеет структуру ватерита, при увеличении концентрации ионов $\mathrm{In}^{3+}$ фаза кальцита возникает в приповерхностном слое микрокристаллов, в то время как объем образца все еще имеет структуру ватерита. Можно было бы ожидать, что зарождение новой фазы в образцах $\mathrm{Lu}_{0.99-x} \mathrm{RE}_{x} \mathrm{Eu}_{0.01} \mathrm{BO}_{3}$, вне зависимости от исходного структурного состояния образца, будет происходить с

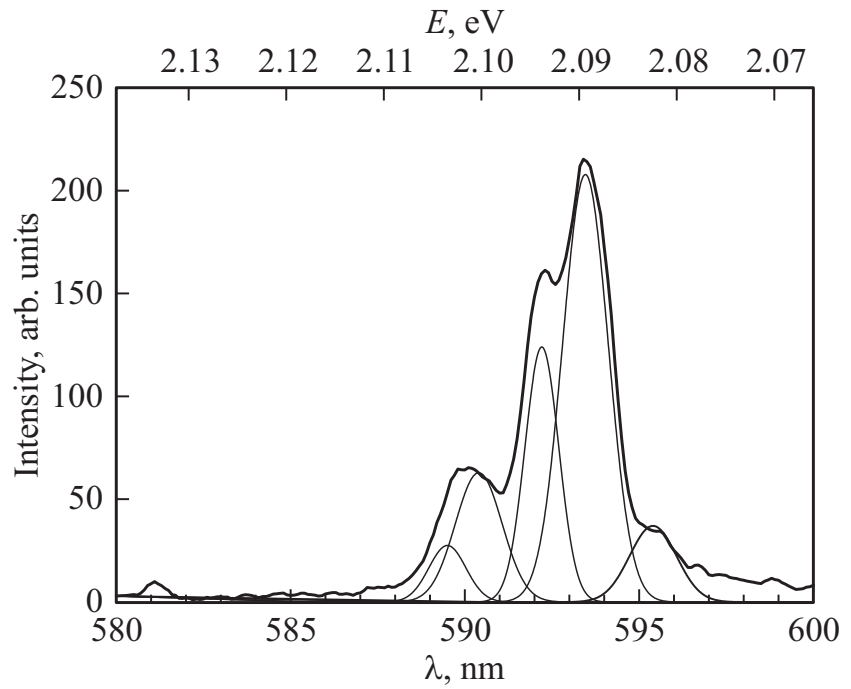

Рис. 8. Разложение полосы 588-596 nm (рис. 7, спектр 6) на составляющие. При разложении спектра использовалась энергетическая шкала, после разложения спектра осуществлялся переход от $\mathrm{eV}$ к $\mathrm{nm}$.

его поверхности. Однако приведенные экспериментальные данные по исследованию фазообразования в соединениях $\mathrm{Lu}_{0.99-x} \mathrm{Gd}_{x} \mathrm{Eu}_{0.01} \mathrm{BO}_{3}$ не подтверждают это предположение.

Образование фазы ватерита в объеме микрокристаллов со структурой кальцита не будет сопровождаться возникновением механических напряжений, препятствующих этому процессу, поскольку плотность кристаллов бората лютеция со структурой ватерита больше плотности кристаллов со структурой кальцита [18].

Таким образом, из-за различных плотностей кальцитной и ватеритной фаз образование кальцита в образцах, имеющих исходную структуру ватерита, происходит вначале в приповерхностных областях образца, в то время как образование ватерита в исходной кальцитной модификации осуществляется вначале в объеме микрокристалла.

В настоящей работе показано, что образцы твердых растворов $\mathrm{Lu}_{0.99-x} \mathrm{Gd}_{x} \mathrm{Eu}_{0.01} \mathrm{BO}_{3}$ при $0 \leq x \leq 0.05$ представляют собой крупные микрокристаллы со структурой кальцита, при $x>0.05$ в образцах появляется фаза ватерита как в виде мелких микрокристаллов размером $1-2 \mu \mathrm{m}$, так и внутри крупных микрокристаллов (15-20 $\mu \mathrm{m})$, при $x>0.1$ весь образец состоит из микрокристаллов со структурой ватерита.

Следует отметить, что при рентгенофазовом анализе мы получаем усредненную по объему образца информацию о его структуре, поскольку глубина проникновения рентгеновского излучения и максимальный размер исследованных микрокристаллов близки и составляют $\sim 10-15 \mu \mathrm{m}$ (рис. 4). В то же время, как отмечалось ранее, структуры на поверхности и в объеме образца могут существенно отличаться [13-15]. Поэтому исполь- 
зование оптически активных и структурно-чувствительных меток, которые дают возможность исследования структуры приповерхностного слоя и объема образца $\mathrm{Lu}_{0.98-x} \mathrm{Gd}_{x} \mathrm{Eu}_{0.02} \mathrm{BO}_{3}$ в зависимости от концентрации $\mathrm{Gd}^{3+}$, позволяет получать более полную информацию об изменении структурного состояния исследуемых соединений.

\section{2. Спектры возбуждения люминесценции ортоборатов $\mathrm{Lu}_{0.99-x} \mathrm{Gd}_{x} \mathrm{Eu}_{0.01} \mathrm{BO}_{3}$}

Спектры возбуждения люминесценции (СВЛ) наиболее интенсивных полос свечения кальцитной и ватеритной модификаций $\mathrm{Lu}_{0.99-x} \mathrm{Gd}_{x} \mathrm{Eu}_{0.01} \mathrm{BO}_{3}$ представлены на рис. 9. СВЛ наиболее интенсивной полосы свечения $\left(\lambda_{\max }=589.8 \mathrm{~nm}\right)$ кальцитной модификации $\mathrm{Lu}_{0.94-x} \mathrm{Gd}_{0.05} \mathrm{Eu}_{0.01} \mathrm{BO}_{3}$ содержит интенсивную коротковолновую полосу $\left(\lambda_{\max }=250 \mathrm{~nm}\right)$ (полосу с переносом заряда ППЗ) и слабые резонансные полосы иона $\mathrm{Eu}^{3+}$ $394 \mathrm{~nm}\left({ }^{7} \mathrm{~F}_{0} \rightarrow{ }^{5} \mathrm{~L}_{6}\right)$ и $466-470 \mathrm{~nm}\left({ }^{7} \mathrm{~F}_{0} \rightarrow{ }^{5} \mathrm{D}_{2}\right)$ (рис. 9, спектр 1). Спектры возбуждения люминесценции полос 589.8 и $595.7 \mathrm{~nm}$ совпадают.

Спектр возбуждения люминесценции наиболее интенсивной полосы свечения $\lambda_{\max }=593.3 \mathrm{~nm}$ ватеритной модификации $\mathrm{Lu}_{0.84-x} \mathrm{Gd}_{0.15} \mathrm{Eu}_{0.01} \mathrm{BO}_{3}$ содержит полосу с переносом заряда $\left(\lambda_{\max } \sim 240 \mathrm{~nm}\right)$ и резонансные полосы 394, 466 и $\sim 468.5 \mathrm{~nm}$ (рис. 9, спектр 2). Важно отметить кардинальное различие представленных на рис. 9 спектров возбуждения основных полос люминесценции кальцитной и ватеритной фаз. В СВЛ кальцитной фазы $\mathrm{Lu}_{0.94-x} \mathrm{Gd}_{0.05} \mathrm{Eu}_{0.01} \mathrm{BO}_{3}$ интенсивность коротковолновой полосы $\left(\lambda_{\max }=250 \mathrm{~nm}\right)$ более чем в 20 раз превосходит наиболее интенсивную резонансную полосу $\left(\lambda_{\max }=394 \mathrm{~nm}\right)$. В то же время, в СВЛ ортобората $\mathrm{Lu}_{0.84-x} \mathrm{Gd}_{0.15} \mathrm{Eu}_{0.01} \mathrm{BO}_{3}$, имеющего структуру ватерита, амплитуда ППЗ $\left(\lambda_{\max } \sim 240 \mathrm{~nm}\right)$ примерно лишь в $1.5-2$ раза интенсивнее полосы $394 \mathrm{~nm}$.

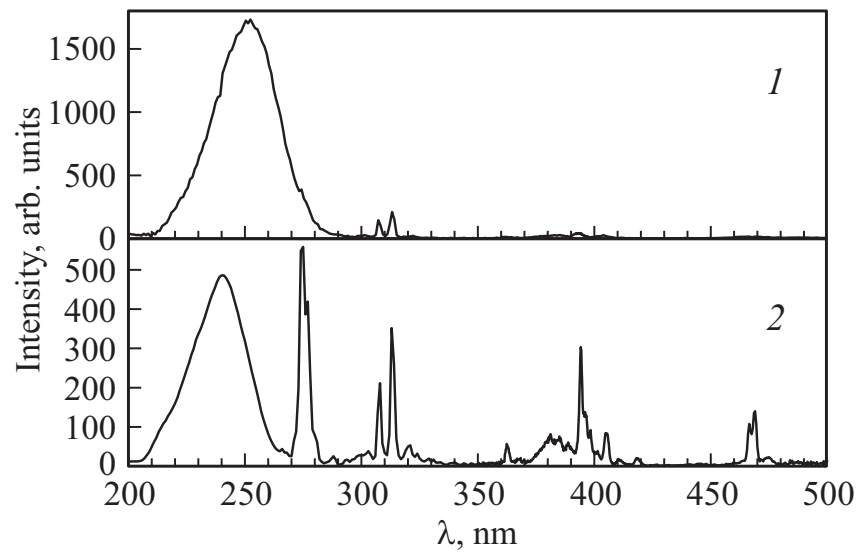

Рис. 9. Спектры возбуждения люминесценции ортоборатов. 1. Крупная фракция микрокристаллов, полученная в результате сепарации $\mathrm{Lu}_{0.925} \mathrm{Gd}_{0.065} \mathrm{Eu}_{0.01} \mathrm{BO}_{3}\left(\lambda_{\max }=589.7 \mathrm{~nm}\right)$; 2. $\mathrm{Lu}_{0.84} \mathrm{Gd}_{0.15} \mathrm{Eu}_{0.01} \mathrm{BO}_{3}\left(\lambda_{\max }=593.3 \mathrm{~nm}\right)$.
Радикальные различия между спектрами люминесценции ионов $\mathrm{Eu}^{3+}$, имеющих локальное окружение, соответствующее фазам кальцита и ватерита, а также слабая интенсивность полос люминесценции, характерных для кальцитной модификации соединений $\mathrm{Lu}_{0.99-x} \mathrm{Gd}_{x} \mathrm{Eu}_{0.01} \mathrm{BO}_{3}$ при резонансном возбуждении ионов $\mathrm{Eu}^{3+}$, позволяют при возбуждении люминесценции образца светом с $\lambda_{\mathrm{ex}}=394 \mathrm{~nm}$ получить информацию о наличии в объеме образца ионов $\mathrm{Eu}^{3+}$, имеющих локальное окружение, соответствующее фазе ватерита.

Следует особо отметить, что в СВЛ $\mathrm{Eu}^{3+}$-центров в образцах $\mathrm{Lu}_{0.99-x} \mathrm{Gd}_{x} \mathrm{Eu}_{0.01} \mathrm{BO}_{3}$ кроме ППЗ и полос резонансного возбуждения ионов $\mathrm{Eu}^{3+}$ наблюдается ряд узких полос (рис. 9, спектры 1,2), которые, согласно данным работ [26-28], соответствуют резонансному возбуждению ионов $\mathrm{Gd}^{3+}, \lambda_{\max }=273.5,276 \mathrm{~nm}$ $\left({ }^{8} S_{7 / 2} \rightarrow{ }^{7} I_{j}\right), 307$ и $312.5 \mathrm{~nm}\left({ }^{8} S_{7 / 2} \rightarrow{ }^{6} P_{7 / 2}\right)$. Свечение ионов $\mathrm{Eu}^{3+}$ при резонансном возбуждении ионов $\mathrm{Gd}^{3+}$ обусловлено передачей энергии от ионов $\mathrm{Gd}^{3+}$ к ионам $\mathrm{Eu}^{3+}$.

\section{7. Заключение}

В настоящей работе проведены исследования структуры, морфологии, ИК-спектров поглощения, а также спектров возбуждения люминесценции и спектров люминесценции приповерхностного слоя и объема микрокристаллов синтезированных при $970^{\circ} \mathrm{C}$ ортоборатов $\mathrm{Lu}_{0.99-x} \mathrm{Gd}_{x} \mathrm{Eu}_{0.01} \mathrm{BO}_{3}$ при $0 \leq x \leq 0.15$.

Показано, что с ростом концентрации Gd происходит последовательная смена двух типов кристаллических фаз. В интервале $0 \leq x \leq 0.05$ твердый раствор ортоборатов является однофазным и имеет структуру кальцита (пр.гр. $R \overline{3} c$ ). При $0.05<x \leq 0.1$ наряду со структурой кальцита появляется фаза ватерита (пр. гр. $C 2 / c)$, а при $x>0.1$ твердый раствор является также однофазным со структурой ватерита (пр. гр. $C 2 / c)$.

Установлено, что одновременно со структурой изменяется и морфология микрокристаллов ортоборатов. При $0 \leq x \leq 0.05$ наблюдаются крупные микрокристаллы $(15-20 \mu \mathrm{m})$, в интервале концентраций ионов $\mathrm{Gd}^{3+}$ $0.05<x \leq 0.1$ наряду с крупными появляются мелкие микрокристаллы $(1-2 \mu \mathrm{m})$, количество которых растет при увеличении $x$, а при $x>0.1$ наблюдаются преимущественно микрокристаллы размером $1-2 \mu \mathrm{m}$.

Методами ИК спектроскопии и рентгенофазового анализа показано, что микрокристаллы размером $1-2 \mu \mathrm{m}$ имеют структуру ватерита (пр.гр. C2/c).

Установлено, что фаза ватерита в соединении $\mathrm{Lu}_{0.99-x} \mathrm{Gd}_{x} \mathrm{Eu}_{0.01} \mathrm{BO}_{3}$ при увеличении концентрации $\mathrm{Gd}^{3+}$ появляется как в объеме крупных микрокристаллов размером 15-20 $\mu \mathrm{m}$ со структурой кальцита, так и в виде микрокристаллов размером $1-2 \mu \mathrm{m}$.

Бораты редкоземельных элементов, легированные европием, имеют высокую интенсивность свечения, 
являются химически и радиационно стойкими, имеют высокую теплопроводность. Поэтому соединение $\mathrm{Lu}_{0.99-x} \mathrm{Gd}_{x} \mathrm{Eu}_{0.01} \mathrm{BO}_{3}$ при $0.05 \leq x \leq 0.15$ можно рассматривать в качестве эффективного люминофора для светодиодов.

\section{Благодарности}

Авторы выражают благодарность ЦКП Института физики твердого тела РАН за исследование образцов методом ИК-спектроскопии, а также их морфологии.

\section{Финансирование работы}

Работа выполнена в рамках госзадания ИФТТ РАН.

\section{Конфликт интересов}

Авторы заявляют, что у них нет конфликта интересов.

\section{Список литературы}

[1] C. Mansuy, J.M. Nedelec, C. Dujardin, R. Mahiou. Opt. Mater. 29, 6, 697 (2007).

[2] Jun Yang, Chunxia Li, Xiaoming Zhang, Zewei Quan, Cuimiao Zhang, Huaiyong Li, Jun Lin. Chem. Eur. J. 14, 14, 4336 (2008).

[3] С.З. Шмурак, В.В. Кедров, А.П. Киселев, И.И. Зверькова. ФTT 55, 2, 336 (2013).

[4] С.3. Шмурак, В.В. Кедров, А.П. Киселев, И.М. Шмытько. ФTT 57, 1, 19 (2015).

[5] С.3. Шмурак, В.В. Кедров, А.П. Киселев, Т.Н. Фурсова, И.М. Шмытько. ФТТ 57, 8, 1558 (2015).

[6] С.3. Шмурак, В.В. Кедров, А.П. Киселев, Т.Н. Фурсова, И.М. Шмытько. ФТТ 58, 3, 564 (2016).

[7] С.3. Шмурак, В.В. Кедров, А.П. Киселев, Т.Н. Фурсова, О.Г. Рыбченко ФТТ 59, 6, 1150 (2017).

[8] С.3. Шмурак, В.В. Кедров, А.П. Киселев, Т.Н. Фурсова, И.И. Зверькова, С.С. Хасанов ФТТ 62, 11, 1888 (2020).

[9] С.З. Шмурак, В.В. Кедров, А.П. Киселев, Т.Н. Фурсова, И.И. Зверькова ФТТ. 62, 12, 2110 (2020).

[10] J. Yang, G. Zhang, L. Wang, Z. You, S. Huang, H. Lian, J. Lin. J. Solid State Chem. 181, 12, 2672 (2008).

[11] М.А. Ельяшевич. Спектроскопия редких земель. ГИТТЛ, M. (1953). $456 \mathrm{c}$.

[12] М.И. Гайдук, В.Ф. Золин, Л.С. Гайгерова. Спектры люминесценции европия. Наука, М. (1974). 195 с.

[13] А.П. Киселев, С.3. Шмурак, Б.С. Редькин, В.В. Синицын, И.М. Шмытько, Е.А. Кудренко, Е.Г. Понятовский. ФТТ 48, 8, 1458 (2006).

[14] S.Z. Shmurak, A.P. Kiselev, N.V. Klassen, V.V. Sinitsyn, I.M. Shmyt'ko, B.S. Red'kin, S.S. Khasanov. IEEE Trans. Nucl. Sci. 55, 1-3, 1128 (2008).

[15] С.3. Шмурак, А.П. Киселев, Д.М. Курмашева, Б.С. Редькин, В.В. Синицын. ЖЭТФ 137, 5, 867 (2010).

[16] D. Hreniak, E. Zych, L. Kepinski, W. Strek. J. Phys. Chem. Solids 64, 1, 111 (2003).

[17] J. Hölsä. Inorg. Chim. Acta 139, 1-2, 257 (1987).

[18] E.M. Levin, R.S. Roth, J.B. Martin. Am. Miner. 46, 9-10, 1030 (1961).
[19] G. Chadeyron, M. El-Ghozzi, R. Mahiou, A. Arbus, C. Cousseins. J. Solid State Chem. 128, 2, 261 (1997).

[20] Zhi-Jun Zhang, Teng-Teng Jin, Meng-Meng Xu, Qing-Zhen Huang, Man-Rong Li, Jing-Tai Zhao. Inorg. Chem. 54, 969 (2015).

[21] А.Г. Рябухин. Изв. Челябинского науч. центра 4,33 (2000).

[22] Y. Wu, D. Ding, F. Yang, S. Pan, G. Ren. Mater. Res. Bull. 47, 1, 106 (2012).

[23] C.E. Weir, E.R. Lippincott. J. RES. Natl. Bur. Std. 65A, 3, 173 (1961).

[24] J.P. Laperches, P. Tarte. Spectrochim. Acta 22, 7, 1201 (1966).

[25] D. Boyer, F. Leroux, G. Bertrand, R. Mahiou. J. Non-Cryst. Solids 306, 2, 110 (2002).

[26] Е.В. Мальчукова, А.И. Непомнящих, В. Boizot, Т.С. Шамирзаев, G. Petite. ФТT 52, 9, 1789 (2010).

[27] L. Skuja. J. Non-Cryst. Solids 239, 1-3, 16 (1998).

[28] G.H. Dieke, H.M. Crosswhite. Appl. Opt. 2, 7, 675 (1963).

Редактор Т.Н. Василевская 